\title{
Plasma Acute Phase Proteins as Predictors of Chronic Lung Allograft Dysfunction in Lung Transplant Recipients
}

This article was published in the following Dove Press journal: Journal of Inflammation Research

\author{
Sabina Janciauskiene, ${ }^{1,2, *}$ \\ Pierre-Joseph Royer, ${ }^{3, *}$ \\ Jan Fuge, (DD 'Sabine Wrenger, \\ Joanna Chorostowska- \\ Wynimko, (D) ${ }^{2}$ \\ Christine Falk, (iD) ${ }^{4,5}$ \\ Tobias Welte, (ID) \\ Martine Reynaud-Gaubert, ${ }^{6}$ \\ Antoine Roux, ${ }^{7-9}$ Adrien Tissot, ${ }^{3}$ \\ Antoine Magnan ${ }^{3}$ \\ 'Department of Pulmonary and Infectious \\ Diseases, BREATH German Center for Lung \\ Research (DZL) Hannover University School, \\ Hannover, Germany; ${ }^{2}$ Department of Genetics \\ and Clinical Immunology, National Institute of \\ Tuberculosis and Lung Diseases, Warsaw, \\ Poland; ${ }^{3} \mathrm{CHU}$ de Nantes, Centre National De \\ Référence Mucoviscidose Nantes-Roscoff, \\ Nantes, France; ${ }^{4}$ Institute of Transplant \\ Immunology, Hannover Medical School, \\ Hannover, Germany; ${ }^{5}$ German Center for \\ Infection Research DZIF Hannover \\ Braunschweig Site, TTU-IICH, Hannover, \\ Germany; ${ }^{6}$ Department ofPulmonary Diseases \\ and Lung Transplantation, CHU Nord de \\ Marseille; IHU - Méditerranée Infection, Aix \\ Marseille Université, Marseille, France; ${ }^{7} \mathrm{Hôpital}$ \\ Foch, Suresnes, France; ${ }^{8}$ Université Versailles \\ Saint-Quentin- en-Yvelines, Versailles, France; \\ ${ }^{9}$ 'Institut du Thorax, Université de Nantes, \\ Nantes, France \\ *These authors contributed equally to this \\ work
}

Correspondence: Sabina Janciauskiene Department of Pulmonary and Infectious Diseases, Hannover Medical School, Feodor-Lynen Str. 23, Hannover 30625, Germany

Tel +49-5 I I-532-7297

Email Janciauskiene.sabina@mh-hannover. de

\begin{abstract}
Cumulating reports suggest that acute phase proteins (APPs) have diagnostic and prognostic value in different clinical conditions. Among others, APPs are proposed to serve as markers that help to control the outcome of transplant recipients. Here, we questioned whether plasma concentrations of APPs mirror the development of chronic lung allograft dysfunction (CLAD). We performed blinded analysis of serial plasma samples retrospectively collected from 35 lung transplanted patients, of whom 25 developed CLAD and 10 remained stable during the follow-up period of 3 to 4.5 years. Albumin (ALB), alpha1-antitrypsin (AAT), high sensitivity C-reactive protein (CRPH), antithrombin-3 (AT3), ceruloplasmin (CER), and alpha2macroglobulin $(\mathrm{A} 2 \mathrm{MG})$ were measured by the nephelometric method. We found that within the first six months post-transplantation, levels of A2MG, CER and AAT were higher in stable patients relative to those who later developed CLAD. Moreover, in stable patient's plasma CRPH levels decreased during the follow-up period whereas opposite, in those developing CLAD, the CRPH gradually increased. The ALB levels became significantly lower at the end of the followup period in CLAD relative to a stable group. A logistic regression model based on A2MG, CER and AT3 at cut-offs levels of $\geq 175.5 \mathrm{mg} / \mathrm{dL}, \geq 37.8 \mathrm{mg} / \mathrm{dL}$ and $\geq 27.35 \mathrm{mg} / \mathrm{dL}$ enabled to discriminate between stable and CLAD patients with a sensitivity of $87.5 \%, 100 \%$ and $62.5 \%$, and specificity of $65.9 \%, 72.7 \%$ and $79.5 \%$, respectively. We identified A2MG (below $175.5 \mathrm{mg} /$ $\mathrm{dL}$ ) as an independent predictor of CLAD (hazard ratio $11.5,95 \%$ CI (1.5-91.3), $\mathrm{p}<0.021)$. Our findings suggest that profiles of certain APPs may help to predict the development of lung dysfunction at the very early stages after transplantation.
\end{abstract}

Keywords: acute phase proteins, transplantation, allograft dysfunction

\section{Introduction}

The acute phase response is the systemic reaction of the organism against inflammation, infection and tissue injury involving a wide range of pathophysiological responses to minimize damage while enhancing the repair process. One of these reactions includes an increase in the production of the acute-phase proteins (APP). These proteins are produced in response to pro-inflammatory cytokines mainly released by hepatocytes, but also by monocytes, endothelial and epithelial cells, and other cells. The functions of APPs are regarded as important in activating the complement system, neutralizing enzymes, scavenging free heme and radicals, and in modulating the host's immune response. ${ }^{1}$

Importantly, changes in various APPs occur at different time points and to different degrees. For example, in individuals with severe infection ceruloplasmin (CER) exhibits

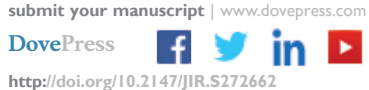


relatively modest increase (typically about a 50\% increase), alpha1-antitrypsin (AAT) increases about 2-5-fold whereas C-reactive protein may exhibit a dramatic increase (1000-fold or more). In contrast, plasma concentrations of some APPs, such as albumin, decrease during the acute-phase response. ${ }^{2}$ These orchestrated alterations in specific APP levels during inflammatory states serve as biomarkers of immune system perturbation, used for diagnosis and prognosis of diseases, monitoring responses to treatment, and for general health screening. Indeed, the application of APPs for different purposes recently increases. For example, certain APPs are used to predict the effect of cancer therapy. ${ }^{3}$ Cumulating reports suggest that APPs have value in the prognosis of the survival of heart, kidney, and liver transplants. ${ }^{4}$ Although the changes in APPs levels are not organ specific, they can serve as markers of the systemic alterations that help controlling the survival of organ recipients.

Lung transplantation (LuTx) is the only therapeutic option for many patients with end-stage lung diseases. Over the last decades the advancements in perioperative care and post-transplant medical management have led to significant improvements in a short-term survival after LuTx whereas longer-term outcomes remain poor compared to those of other types of solid organ transplantations. The main problem in achieving a long-term survival is a development of chronic lung allograft dysfunction (CLAD) which physiopathology is still only partially understood. Currently, no treatment is available to reverse CLAD after diagnosis; however, early identification of CLAD would allow targeted strategies to reverse the progression of the disease before irreversible allograft damage occurs. Opposite, the management of lung recipients identified as having a low risk of developing CLAD could allow personalized health care to improve quality of life. For such risk stratification, we need reliable biomarkers that can predict early development of CLAD.
To the best of our knowledge, the prognostic importance of APPs in LuTx patients has not yet been described. Consequently, in this work, we questioned whether plasma profiles of certain APPs can help to predict the development of CLAD. We performed blinded analysis of serial plasma samples retrospectively collected from 35 lung transplanted patients, of whom 25 developed CLAD and 10 remained stable during the follow-up period of 3 to 4.5 years. Levels of "negative" (albumin (ALB)) and "positive" APPs like alpha1-antitrypsin (AAT), high sensitivity C-reactive protein (CRPH), antithrombin-3 (AT3), ceruloplasmin (CER), and alpha2-macroglobulin (A2MG) were determined at clinical laboratory.

\section{Patients and Methods}

\section{Patients}

Our study included 35 LuTx patients, of whom 25 developed CLAD and 10 remained stable during the follow-up period of 3 to 4.5 years (Figure 1). Patients were randomly selected based on the availability of repeatedly collected plasma samples in the biobank of the multicenter longitudinal cohort of Lung Transplantation (COLT) monitoring patients during 5 years following lung transplantation in order to detect predictive factors of CLAD (Cohort of Lung Transplantation, NCT00980967). ${ }^{5}$ Because COLT is a multicentric cohort, daily clinical practice may induce discrepancies between clinical data that are not possible to harmonize. Therefore, all patients were phenotyped by a blind adjudication committee according to ISHLT/ERS/ ATS guidelines based on pulmonary function tests and chest imaging. Patients with uncertain diagnosis or confounding factors were excluded allowing an unequivocal diagnosis. This approach has been validated in other studies derived from COLT cohort. $^{6-9}$ Patients with a mixed phenotype of CLAD [12 with bronchiolitis obliterans

\section{The COLT cohort}

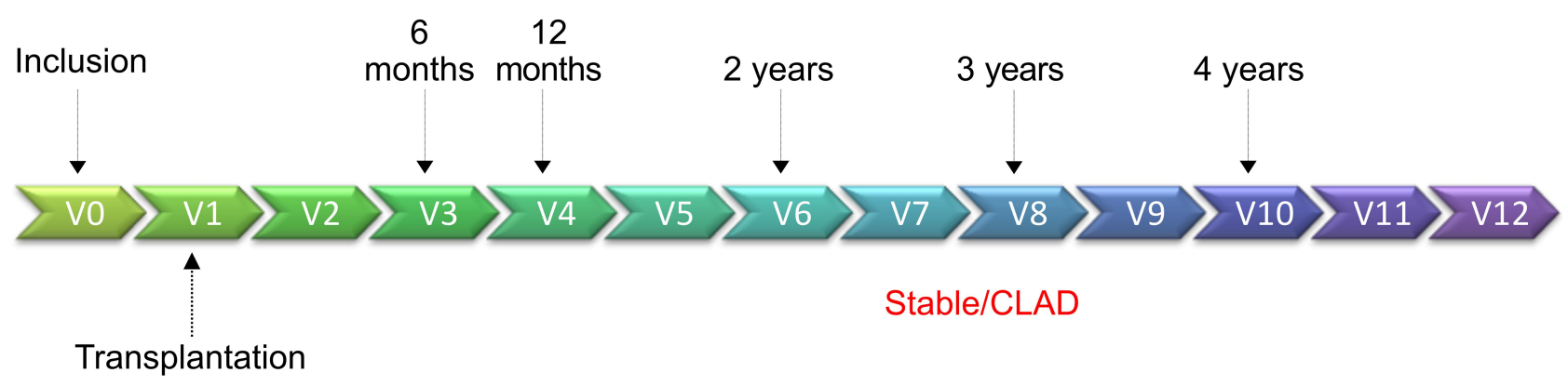

Figure I Schematic representation of sample collection. Samples from different visits were assigned to follow-up periods I-6 months (baseline), I-2 years, 3-4.5 years. 
syndrome (BOS) diagnosis and 13 with restrictive allograft syndrome (RAS)] were compared to those remaining stable during follow-up period. Except for post-transplant therapy, patient groups did not differ significantly regarding gender, age, body mass index, and underlying disease (Table 1). Cold ischemia time, known to affect lung function, was similar between the groups as well. The classical immunosuppressive regimen was given to the patients and immunosuppression doses were comparable between groups (Figure 2). The differences occurred only in immunosuppression with azithromycin, which was reported to reverse lung function decline. Therefore, this drug was preferentially given for the CLAD patients (as seen in Table 1) or as previously reported. ${ }^{10}$ In addition, all included patients had no therapy against concurrent cytomegalovirus infection or cellular and humoral rejections within 1 month before or after plasma collection. Although we cannot totally exclude the occurrence of mild episodes, we assume that their impact on APPs is very limited.

Table I Patient Demographics

\begin{tabular}{|c|c|c|c|}
\hline & $\begin{array}{l}\text { Stable, } \\
\mathrm{N}=10\end{array}$ & $\begin{array}{l}\text { CLAD, } \\
\mathrm{N}=25\end{array}$ & p-value \\
\hline Mean age at LuTx (range) & $43.4(20-60)$ & $43.6(15-65)$ & $0.916^{\mathrm{a}}$ \\
\hline \multicolumn{4}{|l|}{ Sex } \\
\hline$M / F(\%)$ & $4 / 6(40 / 60)$ & $9 / 16(36 / 64)$ & 0.341 \\
\hline BMI & 20.1 & 21.4 & $0.417^{\mathrm{a}}$ \\
\hline \multicolumn{4}{|l|}{ Pathology leading to LuTx } \\
\hline Emphysema/COPD. N (\%) & $4(40)$ & $12(48)$ & 0.391 \\
\hline CF, N (\%) & $5(50)$ & $6(24)$ & \\
\hline PAH, N (\%) & - & $2(8)$ & \\
\hline IPF, N (\%) & I (10) & $5(20)$ & \\
\hline \multicolumn{4}{|l|}{ Type of LuTx } \\
\hline Double lung, $N(\%)$ & $10(100)$ & $18(72)$ & 0.188 \\
\hline Single lung, $N(\%)$ & - & $6(24)$ & \\
\hline Heart/Lung, N (\%) & - & I (4) & \\
\hline \multicolumn{4}{|l|}{ Induction } \\
\hline Basiliximab, N (\%) & I (10) & $3(12)$ & 0.518 \\
\hline Thymoglobulin, N (\%) & $7(70)$ & $14(56)$ & \\
\hline None, $\mathrm{N}(\%)$ & $2(20)$ & $8(32)$ & \\
\hline \multicolumn{4}{|l|}{ Immunosuppressive } \\
\hline Steroids, N (\%) & $10(100)$ & $24(96)$ & n.a. \\
\hline Tacrolimus/Cyclosporin, N/N (\%/\%) & $9 / 1(90 / 10)$ & $23 / 2(92 / 8)$ & 0.822 \\
\hline MMF/MPA, N(\%) & $10(100)$ & $25(100)$ & n.a. \\
\hline Azithromycin, N (\%) & $3(30)$ & $18(72)$ & 0.018 \\
\hline
\end{tabular}

Notes: $\mathrm{p}$-values calculated with ${ }^{\mathrm{a}}$ Mann-Whitney-U or chi square test; bold highlights statistical significance.

Abbreviations: BMI, body mass index; CF, cystic fibrosis; CLAD, chronic lung allograft dysfunction; COPD, chronic obstructive pulmonary disease; F, female; IPF, idiopathic pulmonary fibrosis; M, male; MMF, mycophenolate mofetil; MPA, mycophenolic acid; n.a, not applicable; PAH, pulmonary arterial hypertension.
Plasma collection and pulmonary tests were performed the day of the transplantation, 1 and 6 months after the transplantation and every 6 months thereafter up to 4.5 years.

\section{Ethical Statement}

All patient material and clinical data were collected for the COLT cohort after approval by the institutional ethics board of the Nantes University Hospital (Comité de Protection des Personnes Ouest 1-Tours, 2009-A00036 -51). The trial was conducted in accordance with the Declaration of Helsinki. Written informed consent was obtained for all material from each patient. Patient material was donated voluntarily in accordance with the Declaration of Istanbul. All organ donors gave informed written consent to donate.

\section{Plasma APPs Analysis}

Plasma concentrations of albumin (ALB), alpha1-antitrypsin (AAT), high sensitivity C-reactive protein (CRPH), antithrombin-3 (AT3), ceruloplasmin (CER), and alpha2-macroglobulin (A2MG) were measured blindly in 160 samples using the nephelometric method (IMMAGE 800 Protein Chemistry Analyzer, Beckman Coulter Inc., CA, USA) in the Department of Genetics and Clinical Immunology at the National Institute of Tuberculosis and Lung Diseases, Warsaw. Analysis sensitivity for measured APPs was: ALB (22.2 mg/dL), AAT (10 mg/dL), CRPH $(0.02 \mathrm{mg} / \mathrm{dL})$, AT3 $(5 \mathrm{mg} / \mathrm{dL})$, CER $(2 \mathrm{mg} / \mathrm{dL})$ and A2MG $(40 \mathrm{mg} / \mathrm{dL})$, All plasma samples were analysed at the same time, in order to control for testing variability.

\section{Statistical Analysis}

The IBM SPSS Statistics (version 26.0, IBM Corp., Armonk, New York) and STATA (version 13.0, StataCorp, College Station, Texas) statistical software programs were used to analyze the data. Categorical variables are shown as numbers (n) and percentages (\%). Continuous variables are shown as median (interquartile range, IQR), unless indicated otherwise. For comparisons of patient groups Fisher exact test, chi-square test, Mann-Whitney $U$-test, or 2-sided paired $t$ test were used as appropriate. In order to identify the plasma concentrations with discriminating capabilities between CLAD and stable patients, receiver-operating characteristic curves were drawn and the area under the curve was calculated. The cut-off value for each plasma concentration that resulted in the highest product of sensitivity and specificity was considered the best value for prognostication. The asymptotic 95\% confidence 

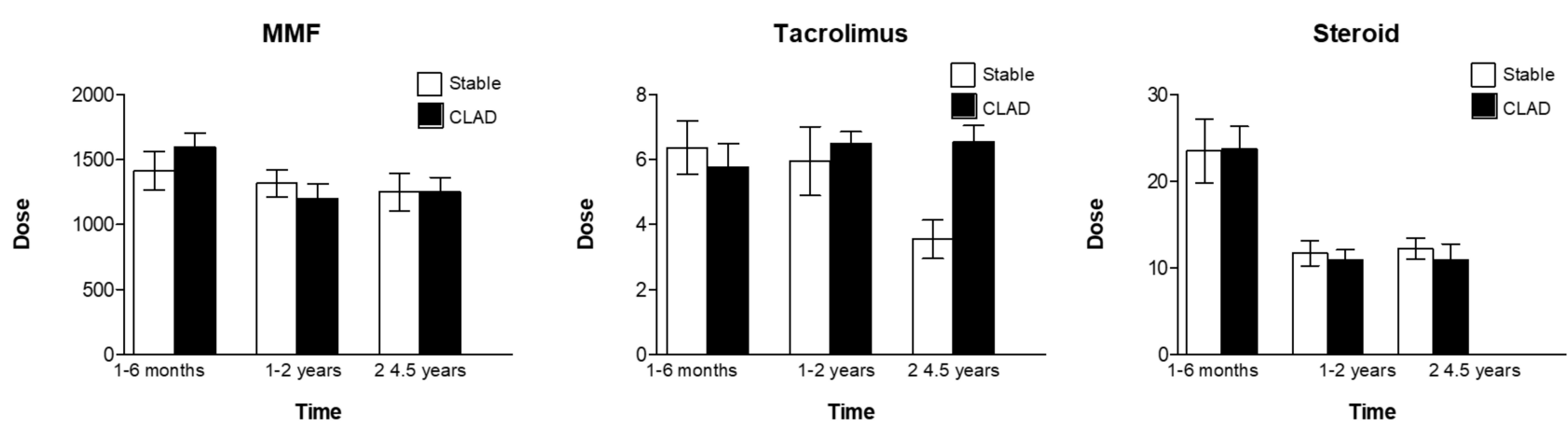

Figure 2 Therapy regime in stable and CLAD patients. Classical immunosuppressive regimen was given to the patients and immunosuppression doses of mycophenolate mofetil (MMF), tacrolimus and steroid were comparable between the stable and CLAD groups. Bars show mean (SD).

interval (CI) as well as the asymptotic $\mathrm{p}$ value under the null hypothesis that the true area $=0.5$ were calculated using a nonparametric method. Categorical variables for each plasma concentration were created whether the patient is above or below the cut-off value of the respective plasma concentration. To determine the impact and risk of CLAD development, logistic regression analysis with the use of the following variables: sex, AT3, AAT, A2MG, CER (all plasma levels being categorical) and patient's age was conducted in single and multivariate predictor models.

\section{Results}

\section{Patient Demographics}

On the basis of the longitudinal follow-up, we retrospectively analysed APPs levels in plasma samples from two homogenous subgroups of LuTx patients: 10 stable and 25 CLAD.

For this cohort plasma samples and pulmonary tests were available from 1 to 6 months post LuTx (named as a "baseline"), from 1 to 2 and 3 to 4.5 years. As illustrated in Figure 3A and B, CLAD diagnosed patients, both BOS and RAS, showed a persistent decline in FEV1 (\% predicted) whereas RAS cases exhibited typical decline in TLC (\% predicted) relative to stable patients who displayed no signs of lung dysfunction during follow-up.

\section{Plasma Levels of APPs}

As presented in Table 2, up to 6 months post-LuTx, baseline plasma levels of A2MG and CER were significantly higher in stable patients relative to those who later developed CLAD. Likewise, the levels of AAT were by $14.7 \%$ higher in stable as compared to CLAD patients. On the other hand, in stable patient's plasma CRPH levels decreased during the follow-up period whereas opposite, in those developing CLAD, levels of CRPH gradually increased. At the end of the follow-up period, stable patients showed significantly lower plasma levels of CRPH than those who developed CLAD. Other measured APPs did not differ significantly
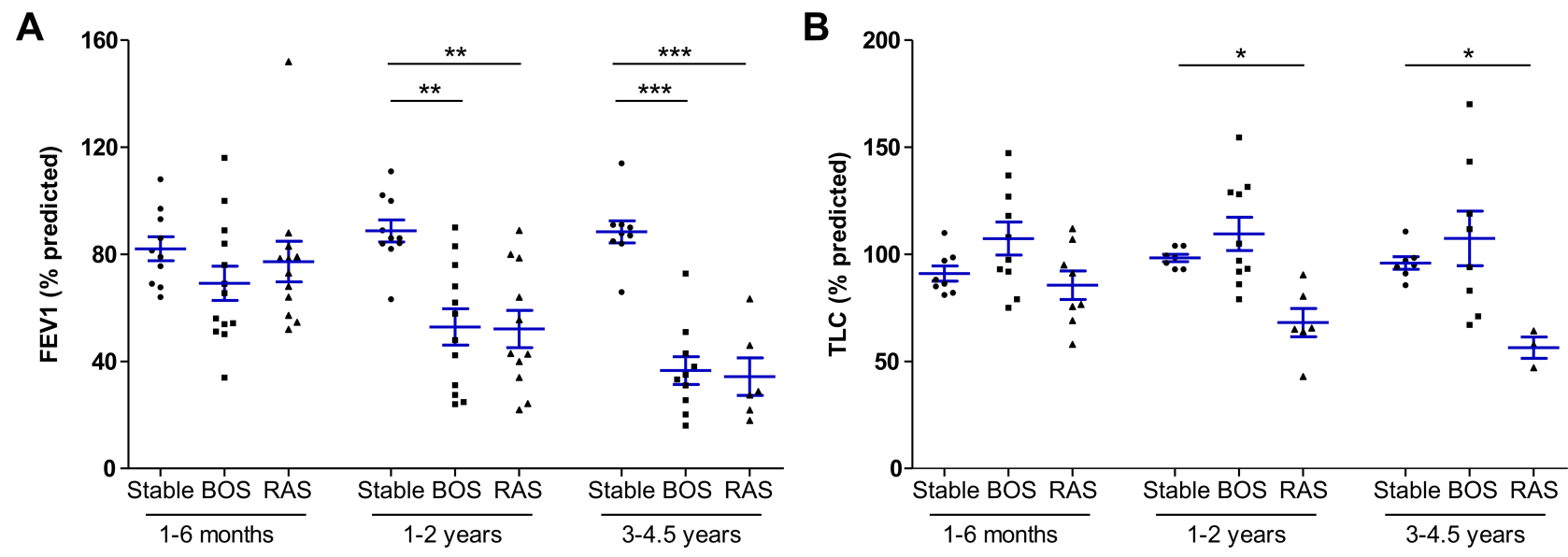

Figure 3 (A, B) Lung function monitoring in stable and CLAD (BOS and RAS) LuTx patients during complete follow-up. Data are shown as mean (SD). Significances were calculated from ANOVA analysis followed by non-parametric Kruskal-Wallis post hoc test using GraphPad Prism 5.0 (GraphPad Software, La Jolla, CA). * P<0.05, ** $\mathrm{p}<0.001$, *** $\mathrm{p}<0.000 \mathrm{I}, \mathrm{FEVI}$, forced expiratory pressure in I second; TLC, total lung capacity. 
Table 2 Acute-Phase Protein Plasma Levels After LuTx in the Time Frames Indicated (Mg/dL), Median (IQR)

\begin{tabular}{|c|c|c|c|c|c|c|}
\hline \multirow[b]{2}{*}{ APP } & \multirow[b]{2}{*}{ Time Frame } & \multicolumn{2}{|l|}{ Stable } & \multicolumn{2}{|l|}{ CLAD } & \multirow[b]{2}{*}{ p-value } \\
\hline & & Median (IQR) & $\mathbf{N}$ & Median (IQR) & $\mathbf{N}$ & \\
\hline \multirow[t]{3}{*}{ AAT } & I-6 months & $168(133-188)$ & 10 & $139(127-152)$ & 25 & 0.047 \\
\hline & $\mathrm{I}-2$ years & $138(115-15 \mid)$ & 10 & $128(\mid 25-152)$ & 23 & 0.710 \\
\hline & $3-4.5$ years & $130(1|3-15|)$ & 9 & $156(|34-17|)$ & II & 0.087 \\
\hline \multirow[t]{3}{*}{ AT3 } & I-6 months & $26.6(24.9-29.7)$ & 10 & $29.5(27.4-32.9)$ & 25 & 0.041 \\
\hline & $\mathrm{I}-2$ years & $28.7(27.1-32.8)$ & 10 & $31.4(28.1-34.6)$ & 23 & 0.203 \\
\hline & $3-4.5$ years & $29.0(26.2-36.7)$ & 9 & $30.4(28.4-32.1)$ & II & 0.909 \\
\hline \multirow[t]{3}{*}{ CRPH } & I-6 months & $\mathrm{I} .27(0.5 \mathrm{I}-3.46)$ & 10 & $0.77(0.37-1.65)$ & 25 & 0.290 \\
\hline & $\mathrm{I}-2$ years & $0.25(0.12-1.09)$ & 10 & $0.47(0.14-1.69)$ & 23 & 0.308 \\
\hline & $3-4.5$ years & $0.31(0.14-0,39)$ & 9 & $1.20(1.03-2.07)$ & II & 0.037 \\
\hline \multirow[t]{3}{*}{ A2MG } & I-6 months & $229(173-272)$ & 10 & $166(135-195)$ & 25 & 0.015 \\
\hline & $\mathrm{I}-2$ years & $214(158-297)$ & 10 & I82 (I28-204) & 23 & 0.046 \\
\hline & $3-4.5$ years & $203(156-26 I)$ & 9 & $168(143-194)$ & II & 0.210 \\
\hline \multirow[t]{3}{*}{ CER } & I-6 months & $47.5(39.0-58.5)$ & 10 & $33.8(28.4-37.0)$ & 25 & 0.000 \\
\hline & $\mathrm{I}-2$ years & $38.1(30.7-49.8)$ & 10 & $32.7(26.1-42.9)$ & 23 & 0.196 \\
\hline & $3-4.5$ years & $40.0(28.6-44.2)$ & 9 & $37.4(32.2-50.6)$ & II & 0.909 \\
\hline \multirow[t]{3}{*}{ ALB } & I-6 months & $3519(2878-3913)$ & 10 & $3373(2983-3726)$ & 25 & 0.884 \\
\hline & $\mathrm{I}-2$ years & $3863(357|-4| 32)$ & 10 & $3625(3290-3930)$ & 23 & 0.240 \\
\hline & $3-4.5$ years & $3860(3596-4002)$ & 9 & $3550(3100-3930)$ & II & 0.063 \\
\hline
\end{tabular}

Notes: Number of patients: I-6 months (Stable/CLAD), 10/25; I-2 years (Stable/CLAD), 10/23; 3-4.5 years (Stable/CLAD), 9/II. p-values calculated with Mann-Whitney$U$ test, bold highlights statistical significance.

Abbreviations: AAT, alphal-antitrypsin; A2MG, alpha2-macroglobulin; ALB, albumin; AT3, antithrombin-3; CER, ceruloplasmin; CRPH, high sensitivity C-reactive protein.

between the groups, except for the ALB levels, which became significantly lower at the end of the follow-up period in CLAD relative to stable group.

\section{Potential APPs to Discriminate Between Stable and CLAD Patients}

A receiver operating characteristics (ROC) curve, the true positive rate (sensitivity) plotted as a function of the falsepositive rate (specificity), revealed that early post LuTx levels of A2MG, CER and AT3 can be considered as putative markers for LuTx patients at high risk to develop CLAD (Figure 4). For A2MG, CER and AT3 the AUCs were 80.4\% $(p<0.001), 88.8 \%(p<0.0001)$ and $72.5 \%(p=0.008)$, respectively, for discriminating stable cases from those who later developed CLAD. Based on the areas under the curve (AUCs), we further assessed the sensitivity and specificity at A2MG, CER and AT3 cut-offs of $\geq 175.5 \mathrm{mg} / \mathrm{dL}, \geq 37.8$ $\mathrm{mg} / \mathrm{dL}$ and $\geq 27.35 \mathrm{mg} / \mathrm{dL}$, for differentiating stable and CLAD cases. Defined cut-offs of A2MG, CER and AT3 had sensitivity $(87.5 \%, 100 \%$ and $62.5 \%)$ and specificity $(65.9 \%, 72.7 \%$ and $79.5 \%)$, respectively.
We tested cut-offs against different logistic models. Single predictor model gave significant association of baseline levels above the defined cut-offs for A2MG, AT3 and CER with subsequent CLAD development (Table 3). When using multivariate linear regression models and simultaneously including all measured APPs as categorical cut-off variables, age and gender, we found that AT3 and A2MG were significantly associated with CLAD development (Table 3).

\section{Discussion}

Several studies provide evidence that measurements of APPs may be of value in diagnosing transplant rejection. Though changes in APPs levels are not organ specific, they allow distinguishing between various post-transplant complications, and when correlating with other biochemical parameters can be an easy, fast and non-invasive assay helping to recognise the reaction of transplant rejection. For example, elevated CRPH concentrations were observed in majority of cases of kidneys and heart transplants, and in GVHD. It has been shown that measurement of $\mathrm{CRPH}$ and $\mathrm{A} 2 \mathrm{MG}$ in urine allows a non-invasive 


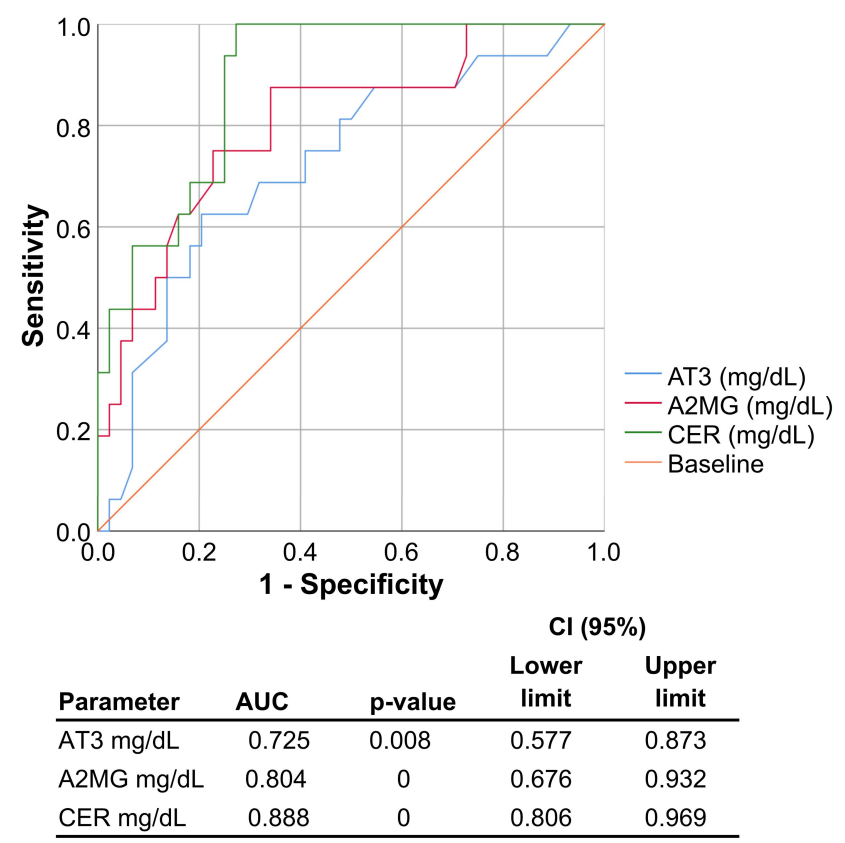

Figure 4 ROC curve showing the true positive rate (sensitivity) plotted as a function of the false-positive rate (specificity) for AT3, A2MG and CER at baseline (I-6 months). Data were analyzed with SPSS statistics software in Hannover by Jan Fuge. AUC, area under the curve; $\mathrm{Cl}$, confidence interval.

diagnostics of acute failure of the transplanted kidneys. ${ }^{11}$ Likewise, increased levels of CRPH were proposed to have prognostic value for the long-term outcome after LuTx. $^{12}$ However, in case of liver transplant rejection, serum CRPH has found to play only a minor role whereas an increase in other APPs, such as AAT, haptoglobin and A2MG, correlated with rejection. ${ }^{13,14}$

We hypothesized that changes in plasma levels of specific APPs relate to the risk of allograft failure among lung transplant recipients. In particular, we sought to demonstrate that elevated levels of CRPH would be associated with decreased lung allograft survival. In concordance with previous studies, we found that plasma CRPH levels increase in patients developing CLAD relative to those who remain stable. Remarkably, this latter increase in CRPH occurred despite the fact that within CLAD group significantly more patients received azithromycin, shown to improve CLAD-free and long-term survival, ${ }^{15}$ and to reduce systemic CRPH levels. ${ }^{15}$ Likewise, another recent study reported that post-transplant azithromycin treatment was not able to improve early lung allograft function. $^{16}$

Human A2MG is one of the major blood proteins that binds a very wide range of substances, especially TGF- $\beta 1$, TNF- $\alpha$ and IL- $1 \beta$, and hormones. A2MG is also capable to inactivate host proteinases, like trypsin, chymotrypsin, elastase and metalloproteinases as well as parasitederived proteinases. Moreover, A2MG binds blood iron, zinc and copper ions stronger than albumin, and acts as serum copper transporter in the human blood. Because the acquisition of metal ions is essential for bacteria survival, one of the host defence strategies against infection is sequestering these metal ions by proteins like A2MG. ${ }^{17}$ Indeed, previous studies have shown that the administration of $\mathrm{A} 2 \mathrm{MG}$ prolongs graft survival and that synthetic micro-vesicles containing A2MG display a significant protective effect in murine sepsis model. CER is the major copper-carrying protein in the blood, plays a role in iron metabolism and exhibits glutathione-peroxidase and nitric oxide-oxidase/S-nitrosating activities. CER is also involved in the modulation of coagulation and angiogenesis. Researchers suggest that CER plays a role in tolerance in organ transplantation as a regulator of inflammation and oxidative injury. ${ }^{18}$ Both $\mathrm{A} 2 \mathrm{MG}$ and CER are important in the maintenance of metal ion levels ${ }^{19}$ while AT3 is the major inhibitor of proteases. All together these proteins are crucial to sustain the pulmonary defence against inhaled pathogens.

Based on our results we propose that the algorithm integrating APPs, including A2MG and CER, may have

Table 3 Cut-Off Levels for APPs at Baseline Derived by ROC Analysis Used in Single Predictor and Multivariate Logistic Models

\begin{tabular}{|c|c|c|c|c|}
\hline \multirow[b]{2}{*}{ Cut-Off at Baseline } & \multicolumn{2}{|c|}{ Single Predictor Model } & \multicolumn{2}{|c|}{ Multivariate Model } \\
\hline & OR (95\% Cl) & p-value & OR (95\% Cl) & p-value \\
\hline AT3 $\geq 27.35 \mathrm{mg} / \mathrm{dL}$ & $10.8(1.8-64.1)$ & 0.008 & $13.7(\mid .8-107.2)$ & 0.013 \\
\hline A2MG $\geq 175.5 \mathrm{mg} / \mathrm{dL}$ & II.5 (I.5-9|.3) & 0.021 & 11.5 (|.5-9|.3) & 0.021 \\
\hline AAT $\geq 169 \mathrm{mg} / \mathrm{dL}$ & $4.1(1.4-3.2)$ & 0.073 & & \\
\hline CER $\geq 37.8 \mathrm{mg} / \mathrm{dL}$ & $2.6(0.96-6.6)$ & 0.010 & & \\
\hline Age & $1.0(0.9-1.0)$ & 0.836 & & \\
\hline Male sex & $1.9(0.4-8.5)$ & 0.395 & & \\
\hline
\end{tabular}

Abbreviations: AAT, alphal-antitrypsin; A2MG, alpha2-macroglobulin; AT3, antithrombin-3; CER, ceruloplasmin; OR, odds ratio; bold highlights statistical significance. 
clinical value in predicting risk for CLAD development at the very early stage, within the first 6 months after LuTx, and thus allowing early targeting therapies. As the methods for the determination of APP levels are available in clinical diagnostic laboratories and this analysis is only minimally invasive for the patient, studies enrolling larger LuTx cohorts can help to validate whether post-transplant profiles of plasma APPs are useful in identifying patients at an increased risk of CLAD development.

One of the limitations of our study is the small number of LuTx patients in each group. Repeating similar study with more CLAD patients divided in BOS or RAS phenotypes could be useful to evaluate APPs during BOS and RAS development. Another limitation is the lack of a validation cohort to adjust for multiple comparisons. On the other hand, included groups of patient groups were very well matched, which is a benefit of this small sample size cohort. Thus, this study does provide provocative data that should be validated in a larger preferably prospective multicenter study as it clearly demonstrates that different APPs might be involved in LuTx patient outcomes, which may allow the development of targeted therapies in the future.

\section{Conclusion}

Evaluation of inflammatory processes via monitoring of APPs concentrations may allow earlier diagnosis of CLAD development and enable earlier interventions than using conventional lung function tests.

\section{Data Sharing Statement}

The authors confirm that all data underlying the findings are fully available without restriction. Any data intended for sharing will be de-identified. Data are available from the GEO database at: http:/www.ncbi.nlm.nih.gov/geo/ query/acc.cgi?token=epkbaewellmjhuv\&acc=GSE38267.

\section{Acknowledgments}

The funders/sponsors do not participate in the conception of the study, the interpretation of the data, the preparation of the manuscript, or the approval of the finished manuscript for publication.

\section{Funding}

Study in part was supported by National Science Centre, Poland. Grant number 2015/17/B/NZ5/01370 and the Centre de Ressource Biologique of nantes University Hospital.

\section{Disclosure}

J.C.W. reports grants, personal fees and non-financial support from CelonPharma, CSL Behring, Grifols, AstraZeneca; personal fees and non-financial support from Abbvie, Pfizer, MSD, BMS; personal fees from GSK, Lekam, Novartis, Takeda; grants and personal fees from Boehringer-Ingelheim, outside the submitted work. T. W. reports grants from German Ministry of Research and Education, during the conduct of the study; personal fees from CLS Behring and Grifols, outside the submitted work. The authors report no other conflicts of interest in this work.

\section{References}

1. Janciauskiene S, Welte T, Mahadeva R. Acute phase proteins: structure and function relationship. In: Veas F, editor. Acute Phase Proteins: Regulation and Functions of Acute Phase Proteins. London, UK: Intech Open; 2011.

2. Gruys E, Toussaint MJ, Niewold TA, Koopmans SJ. Acute phase reaction and acute phase proteins. J Zhejiang Univ Sci B. 2005;6B (11):1045-1056. doi:10.1631/jzus.2005.B1045

3. Pang WW, Abdul-Rahman PS, Wan-Ibrahim WI, Hashim OH. Can the acute-phase reactant proteins be used as cancer biomarkers? Int J Biol Markers. 2010;25(1):1-11. doi:10.1177/17246008100 2500101

4. Watson CJ, Dark JH. Organ transplantation: historical perspective and current practice. Br J Anaesth. 2012;108(Suppl 1):i29-42. doi:10.1093/bja/aer384

5. Tissot A, Foureau A, Brosseau C, et al. COLT: 10 ans de recherche en transplantation pulmonaire, résultats et perspectives. Rev Mal Respir. 2018;35(7):699-705. doi:10.1016/j.rmr.2018.06.007

6. Brosseau C, Danger R, Durand M, et al. Blood CD9 + B cell, a biomarker of bronchiolitis obliterans syndrome after lung transplantation. Am J Transplant. 2019;19(11):3162-3175. doi:10.1111/ajt.15532

7. Danger R, Royer P-J, Reboulleau D, et al. Blood gene expression predicts bronchiolitis obliterans syndrome. Front Immunol. 2018;8:1841. doi:10.3389/fimmu.2017.01841

8. Durand M, Lacoste P, Danger R, et al. High circulating CD4 + CD25 hi FOXP3 + T-cell sub-population early after lung transplantation is associated with development of bronchiolitis obliterans syndrome. $J$ Heart Lung Transplant. 2018;37(6):770-781. doi:10.1016/j. healun.2018.01.1306

9. Koutsokera A, Royer PJ, Antonietti JP, et al. Development of a multivariate prediction model for early-onset bronchiolitis obliterans syndrome and restrictive allograft syndrome in lung transplantation. Front Med. 2017;4:109. doi:10.3389/ fmed.2017.00109

10. Pain M, Royer P-J, Loy J, et al. T cells promote bronchial epithelial cell secretion of matrix Metalloproteinase-9 via a C-C chemokine receptor type 2 pathway: implications for chronic lung allograft dysfunction. $\mathrm{Am}$ J Transplant. 2017;17(6):1502-1514. doi:10.1111/ajt.14166

11. Steinhoff J, Einecke G, Niederstadt C, et al. Renal graft rejection or urinary tract infection? The value of myeloperoxidase, C-reactive protein, and alpha2-macroglobulin in the urine. Transplantation. 1997;64(3):443-447.

12. Vos R, Vanaudenaerde BM, De Vleeschauwer SI, et al. Circulating and intrapulmonary $\mathrm{C}$-reactive protein: a predictor of bronchiolitis obliterans syndrome and pulmonary allograft outcome. J Heart Lung Transplant. 2009;28(8):799-807. doi:10.1016/j.healun.2009.05.011 
13. Izumi S, Hughes RD, Langley PG, Pernambuco JR, Williams R. Acute phase response after liver transplantation for fulminant hepatic failure and cirrhosis. Transpl Int. 1995;8(5):340-345. doi:10.1111/ j.1432-2277.1995.tb01533.x

14. Maury CP, Teppo A-M, Hockerstedt K. Acute phase proteins and liver allograft rejection. Liver. 2008;8(2):75-79. doi:10.1111/j.16000676.1988.tb00971.x

15. Vos R, Vanaudenaerde BM, Verleden SE, et al. Anti-inflammatory and immunomodulatory properties of azithromycin involved in treatment and prevention of chronic lung allograft rejection. Transplantation. 2012;94(2):101-109. doi:10.1097/TP.0b013e31824db9da

16. Van Herck A, Frick AE, Schaevers V, et al. Azithromycin and early allograft function after lung transplantation: a randomized, controlled trial. J Heart Lung Transplant. 2019;38(3):252-259. doi:10.1016/j. healun.2018.12.006
17. Porcheron G, Garenaux A, Proulx J, Sabri M, Dozois CM. Iron, copper, zinc, and manganese transport and regulation in pathogenic Enterobacteria: correlations between strains, site of infection and the relative importance of the different metal transport systems for virulence. Front Cell Infect Microbiol. 2013;3:90. doi:10.3389/ fcimb.2013.00090

18. Wang P-W, Wu T-H, Pan T-L, Chen M-H, Goto S, Chen C-L. Integrated proteome and cytokine profiles reveal ceruloplasmin eliciting liver allograft tolerance via antioxidant cascades. Front Immunol. 2018;9:2216. doi:10.3389/fimmu.2018.02216

19. Schaefer B, Effenberger M, Zoller H. Iron metabolism in transplantation. Transpl Int. 2014;27(11):1109-1117. doi:10.1111/ tri. 12374

\section{Publish your work in this journal}

The Journal of Inflammation Research is an international, peerreviewed open-access journal that welcomes laboratory and clinical findings on the molecular basis, cell biology and pharmacology of inflammation including original research, reviews, symposium reports, hypothesis formation and commentaries on: acute/chronic inflammation; mediators of inflammation; cellular processes; molecular mechanisms; pharmacology and novel anti-inflammatory drugs; clinical conditions involving inflammation. The manuscript management system is completely online and includes a very quick and fair peerreview system. Visit http://www.dovepress.com/testimonials.php to read real quotes from published authors. 